\title{
KNOWLEDGE, ATTITUDES AND PRACTICES (KAP) ON GOOD MANUFACTURING PRACTICES (GMP) AMONG FOOD HANDLERS IN TERENGGANU HOSPITALS
}

\author{
NORHASLINDA R. ${ }^{1}$, NORHAYATI A.H. ${ }^{1}$, MOHD ADZIM KHALILI R. ${ }^{* 1,2,3}$
}

1 School of Nutrition and Dietetics, Faculty of Health Sciences, Universiti Sultan Zainal Abidin (UniSZA), Gong Badak Campus, 21300 Kuala Nerus, Terengganu, Malaysia, ${ }^{2}$ Institute for Community Development \& Quality of Life, Universiti Sultan Zainal Abidin, Gong Badak Campus, 21300 Kuala Nerus, Terengganu Darul Iman, ${ }^{3}$ Centre for Continuing Education (CCE), Universiti Sultan Zainal Abidin, Gong Badak Campus, 21300 Kuala Nerus, Terengganu Darul Iman. Email: mohdadzim@unisza.edu.my

Received: 22 May 2016 Revised and Accepted: 09 Sep 2016

\section{ABSTKACI}

Objective: This study was conducted to study the level of knowledge, attitudes and practices (KAP) on good manufacturing practices (GMP) among food handlers in Terengganu hospitals.

Methods: A cross-sectional study was done with four hospitals involved. Then, sampling method used was purposive convenience sampling. The data had been collected using a method of a questionnaire and being analyzed by using Statistical Package for Social Science (SPSS) 20.0 version.

Results: The findings from this study indicate that food handlers in four Terengganu hospitals have a good level of knowledge (83.0 \pm 1.51 ), attitudes $(87.2 \pm 3.42)$ and practices $(90.7 \pm 1.76)$ regarding GMP. Results show that the association between socio-demographic data factors and variables of level KAP on GMP had significant value. The socio-demographic data involves were gender, ages, working experiences and attendance of training courses. In the other hand, a positive correlation was pointed out for three levels each, between knowledge and attitudes ( $\mathrm{r}=0.13)$, knowledge and practices $(\mathrm{r}=0.24)$, and between attitudes and practices $(\mathrm{r}=0.42)$. However, only level practices and attitudes show significant correlation with $\mathrm{p}<0.05$.

Conclusion: As the conclusion, effective and compulsory food safety training on a regular and ongoing basis should be highlighted and conducted for all food service employees in order to minimize the prevalence of foodborne hazards.

Keywords: GMP, Knowledge, Attitude, Practices, Scores, Correlation

(c) 2016 The Authors. Published by Innovare Academic Sciences Pvt Ltd. This is an open access article under the CC BY license (http://creativecommons. org/licenses/by/4. 0/) DOI: http://dx.doi.org/10.22159/ijpps.2016v8i11.13000

\section{INTRODUCTION}

World Health Organization (WHO) [1] had informed that one in three persons in rural areas may be borne on by foodborne illness each year. Growing of Malaysian population with 28.34 million in 2010 make the expectations and demand by health community are on the rise [2]. In 2012, food poisoning was the most vital event for food and waterborne diseases like Giardiasis, Amoebiasis, Hookworm and Ascariasis [3] which led to more than 56 incident rates per 100,000 populations of Malaysian. Other reported communicable infection incident rates in the same year were cholera (2.02), hepatitis A (1.71), typhoid (0.84), and dysentery (0.15). On closer consideration, growth in incidence rates for food poisoning cases in 12 consecutive years had been increased to 25 times [2] which alarmed for more action to be taken.

Food is a product that is rich in nutrients required by microorganisms and may be exposed to contamination with the main sources such as water, air, dust, equipment and others [4]. Many pollutants are being ingested or inhaled by a human that is also contaminating food and plants eventually [5]. Thus, food hygiene is very indispensable to be given by every division of sectors to prevent contamination occurs and continuously contributing to foodborne disease. Center Disease Control and Prevention [6] had revealed that from January 2009 to December 2010 at USA, 790 outbreaks were a laboratory-confirmed illness and virus for most commonly reported an infection, resulted in $42 \%$ of outbreaks; followed by Salmonella, by the majority of eruptions. Foods that were called up to be involved included ground beef, sprouts, cheese, oysters, raw milk, and eggs, the main sources to be exposed to pollution.

The ascent of these outbreaks will create an enormous societal and economic burden on communities and their health systems eventually [8]. Therefore, food safety is a crucial issue to the consumer, food industry and economy. According to Acikel et al. [8], the cost to treat Salmonellosis only is roughly at 1 billion USD due to medical costs and loss of productivity. Therefore, the basic food safety practices in foodservice instituting are critical because half of food-borne illness cases reported were from this area [9]. In addition, WHO [10] also had indicated that it is indispensable to possess an understanding interaction with dominant food safety KAP of food handlers in order to bring down foodborne outbreaks [4].

Food Hygiene Regulations [11] had defined food handlers is each person who involved directly in the provision of food, contact with food and food-contact surfaces and people who handle packaged foods or unpacked foods and food utensils. Today, several efforts had been served to educate and develop the knowledge, attitudes and patterns of food handlers in order to minimize food poisoning outbreaks. In Malaysia, training of food handlers started in 1996 and mostly handled by Food Handlers Training Institutes [11]. The Ministry of Health (MOH) Malaysia based on Food Hygiene Regulation 2009 has required each new food handlers to attend the food handlers training course which was coordinated by the Food Handlers Training Institutes, as food handlers have a major part in preventing food poisoning during food production and dispersion.

In spite of training offered to each food handlers, food handlers must continually invest their knowledge to their attitude and be practiced it. It should be experienced; all food handlers must be certified by institutes accredited by $\mathrm{MOH}$ [12]. Other than that, food safety assurances like GMP, good hygiene practices (GHP) and hazard analysis and critical control point (HACCP) had been known can be implemented in food industries [12] and also to medical products [13]. HACCP system was experienced to be in issue as it was impractical to be caused due to deficiency of awareness, application, knowledge and resources to identify risks. Hence, courses on GMP should be selected first by the small and medium enterprise's (SMEs) before HACCP being applied [14].

Many researchers had done about KAP questionnaire towards institutions such as hotels, schools, universities and others [9, 1521]. Yet, it was recognized that there is no researcher do survey to foodservice staff at Terengganu hospitals. These populations were crucial to being taken as it included institutions with patients, weakened body immune system. In which, they were required to be cooked and served with hygiene and healthy cooking methods. 
Therefore, the primary aim of this research is to examine the level of KAP on GMP among food handlers in Terengganu hospitals.

\section{MATERIALS AND METHODS}

\section{Study design}

The study design was a cross-sectional study. Respondents involved represent food handlers from 4 different districts Terengganu hospitals with mix race and gender. Data were taken at one point in time through the questionnaire of KAP GMP that consists of 4 parts. This survey was conducted from February 2014 until January 2015.

\section{Questionnaire design/Data collection}

Questionnaire involved were prepared based on GMP criteria's. The dependability of a KAP GMP questionnaire designed was determined by a pilot study with 30 food handlers. These respondents were not affected in the last study. By using Cronbach Alpha test, the reliability coefficient test was 0.64 . As an outcome of the particular analysis, several test questions were changed to improve clarity.

\section{Part 1: Demographic data}

For part 1, each subject was required to fulfill in a structured questionnaire for demographic information. It involves gender, race, education degree, military control and others. Meanwhile, part 2, part 3 and part 4 were used to measure the variable of interest in the level of KAP in GMP.

\section{Part 2: Knowledge of GMP}

In part 2, it consists of 11 questions. Each correct solution in the knowledge section carried 2 marks while wrong carried 1 mark and don't know carried 0 marks. This yielded a total score range of 0-16 for knowledge section. In the case of negatively quoted questions, reverse scoring was used. The scores in part 2 were categorized as poor (less than and equal to 50\%), average (51 to 69\%) and good (70\% and above).

\section{Part 3: Attitude of GMP}

In part 3, it consists of 12 questions and each correct answer carried 2 marks while wrong carried 1 mark and don't know carried 0 marks. For Likert scale answers, 'Never' was scored 0 while 'Rarely,' 'Sometimes,' 'Frequently' and 'Always' were scored as 1, 2, 3, and 4, respectively. This gave a score range of 0-34 for part 3. In the case of negatively quoted questions, reverse scoring was used. The scores in part 3 were categorized as poor (less than and equal to 50\%), fair (51 to $69 \%$ ) and good (70\% and above).

\section{Part 4: Practices of GMP}

Meanwhile, part 4 consists of 10 questions. Each correct answer carried 2 marks while wrong carried 1 mark and don't know carried 0 marks. This gave a total score range of $0-20$ for practices section.
In the case of negatively quoted questions, reverse scoring was used. The scores in part 4 were categorized as poor (less than and equal to $50 \%$ ), fair (51 to $69 \%$ ) and good ( $70 \%$ and above).

\section{Statistical analysis}

The data obtained from the study was analyzed and computed by using the Microsoft Excel Spread Sheet and SPSS version 20.0. Descriptive statistic was applied to summarize frequencies from socio-demographic information. In the meanwhile, the level of KAP in GMP also was examined by using descriptive statistics to summarize frequencies. Based on the variables and outcome that were measured, this analysis was relating the correlation among those three variables. Other than that, independent T-test and Oneway ANOVA $(\mathrm{p}<0.05)$ were used to compare levels of KAP with respect to selected test parameters.

\section{RESULTS AND DISCUSSION}

\section{Demographic characteristics of respondents}

Outcomes were examined for 50 respondents that involved from 4 different districts of Terengganu hospitals in this survey. The majority of the respondents were females with 36 respondents. Most of the respondents age between 21 to $30 \mathrm{y}$ old. The results show 18 of them age between 31 to $40 \mathrm{y}$ old, follows with 3 of them ages between 41 to $50 \mathrm{y}$ old and 4 of them ages more than $50 \mathrm{y}$ previous. Most of the respondents were Malays with $96 \%$ and the others were Chinese and others race. All of them did have a formal education with the majority were secondary leavers (72\%) and followed by degree students $(14 \%)$. Then, there were undergraduate levers with 5 respondents and the last was from primary level, 2 respondents.

A sum of $90 \%$ respondents in this study was staff involved in the food service area, while the others $8 \%$ were catering officer and $2 \%$ was a dietitian. Majority with $42 \%$ of the respondents had worked in this area for 1 to $5 \mathrm{y}$ while $16 \%$ had worked more than $10 \mathrm{y}$. And so, the result shows that 14 of them had made between 6 to $10 \mathrm{y}$ old and 7 respondents less than 1-year-old. Virtually all of the respondents (94\%) attend the training linked to food safety [12]. On the other hand, for food safety requirements, all of the respondents confirmed they had taken typhoid immunization injection.

\section{Gender}

Table 1 shows different average mean scores based on gender on the aspect of their KAP-level. The outcomes were tested with three different levels of KAP and it proved that both male and female in the good grade. Nonetheless, female respondents indicate higher scores than male respondents for all three points. However, there was no statistically significant difference in average mean scores of different levels with respect to gender $(\mathrm{p}<0.05)$. Contrast with result get by Siow and Norrakiah [4], in which there was significantly different in average levels of practice with regard to the gender variable $(\mathrm{p}<0.05)$.

Table 1: Mean score on KAP based on gender

\begin{tabular}{llll}
\hline Aspects & Male (N=14) & Female (N=36) & p-value \\
\hline Knowledge & $86.0 \pm 1.31$ & $82.0 \pm 1.56$ & 0.65 \\
Attitude & $88.0 \pm 3.30$ & $87.0 \pm 3.52$ & 0.87 \\
Practice & $92.0 \pm 1.40$ & $90.0 \pm 1.89$ & 0.36 \\
\hline
\end{tabular}

$\mathrm{N}=50$; Values were expressed as mean \pm standard deviation; a significance difference between the means $(\mathrm{p}<0.05)$ by T-test.

\section{Age}

The different levels of KAP of the respondents have been measured in five different age groups as indicated in table 2. An overall score of KAP with respect to this variable was categorized in the good grade. Still, there was only significantly different in average points of attitudes, level with respect to the different age groups variables $(p<0.05)$. In the other hand, it was noted that respondents with highest average mean points of knowledge $(89.6 \pm 1.53)$ and attitudes (95.1 \pm 1.53$)$ were in group age of $41-50$ y old. Meanwhile, the respondents between age 21-30 y old showed lowest averages mean points of attitude $(82.9 \pm 3.85)$ and practices $(88.4 \pm 2.01)$.

\section{Working experiences}

The findings between three levels of KAP with respect to working experiences variable was shown in table 3 . Results show that different levels of KAP with respect to this variable were categorized as the good level. Also, there was significantly different between attitudes level with respect to working experiences variable $(p<0.05)$. It demonstrated that the duration of playing experience will give effects of positive attitudes in food operations. Respondents with working experience less than $6 \mathrm{y}$ acquired the lowest attitudes score $(82.2 \pm 4.04)$ compared to those working more than 6 y $(92.4 \pm 2.10)$. It is a fact that respondents with less playing 
experience had lower scores than more working experience as for knowledge level; respondents with more than 10 y playing experience had the highest score $(87.5 \pm 1.60)$. The Same result revealed for practices level that respondents with working experience less than $1 \mathrm{y}$ acquired the lowest attitudes score (86.5 \pm 2.38$)$ compared to those working more than 6 y $(92.9 \pm 1.28)$.

Table 2: Mean score on KAP based on age groups

\begin{tabular}{|c|c|c|c|c|c|c|c|c|c|}
\hline Aspects & $<20 y$ & 21 & -30 & 31 & -40 & 41 & -50 & $>50 \mathrm{y}$ & p- \\
\hline & $(\mathrm{N}=1)$ & $(\mathrm{N}=24)$ & & $(\mathrm{N}=18)$ & & $(\mathrm{N}=3)$ & & $(\mathrm{N}=4)$ & value \\
\hline Knowledge & 75.0 & 83.6 & \pm 1.44 & 81.6 & \pm 1.66 & 89.6 & \pm 1.53 & $82.8 \pm 1.50$ & 0.63 \\
\hline Attitude & 94.1 & 82.9 & \pm 3.85 & 91.5 & \pm 2.37 & 95.1 & \pm 1.53 & $86.0 \pm 2.36$ & $<0.05^{*}$ \\
\hline Practice & 100.0 & 88.4 & \pm 2.01 & 91.7 & \pm 1.53 & $95.0 \pm 1.0$ & & $95.0 \pm 0.82$ & 0.32 \\
\hline
\end{tabular}

$\mathrm{N}=50$; Values were expressed as mean \pm standard deviation; a significance difference between the means (p<0.05) by One-way ANOVA.

Table 3: Mean score on KAP based on working experience

\begin{tabular}{|c|c|c|c|c|c|}
\hline Aspects & $<1 \mathrm{y}$ & $1-5 y$ & $6-10 y$ & $>10 y$ & p- \\
\hline & $(N=7)$ & $(\mathrm{N}=21)$ & $(N=14)$ & $(\mathrm{N}=8)$ & value \\
\hline Knowledge & $83.0 \pm 1.25$ & $83.9 \pm 1.66$ & $79.0 \pm 1.22$ & $87.5 \pm 1.60$ & 0.21 \\
\hline Attitude & $89.5 \pm 2.23$ & $82.2 \pm 4.04$ & $92.4 \pm 2.10$ & $89.0 \pm 2.71$ & $<0.05^{*}$ \\
\hline Practice & $86.5 \pm 2.38$ & $90.0 \pm 1.92$ & $92.9 \pm 1.28$ & $92.5 \pm 1.41$ & 0.41 \\
\hline
\end{tabular}

$\mathrm{N}=50$; Values were expressed as mean \pm standard deviation; a significance difference between the means $(\mathrm{p}<0.05)$ by One-way ANOVA.

\section{Training course}

Table 4 represents average mean scores between different levels of KAP with respect to the attendances of training classes. From 50 respondents involved in this study, a majority of $94 \%$ reported that they had followed training courses regarding Food Preparation and Safety Course [11]. However, there was no significant difference between levels of KAP with respect to attendance of training courses $(p<0.05)$. This indicated that there was no obvious difference between respondents who had attended courses and between respondents who did not attend courses in levels of KAP.
In contrast with a study done by Siow and Norrakiah [4], the study indicated that there was an obvious difference between respondents who had attended courses $(94.6 \pm 4.9)$ than those without any record of it $(70.3 \pm 9.7)$ were respondents who had attended training courses showed positive attitudes when handling foods. On the other hand, Maizun and Nyi [18] study on socio-demographic features of food handlers and their KAP towards food sanitation showed that food stand had four times significantly higher odds of having inadequate knowledge. The principal cause of this was food handlers who involved in food stall/hawkers were not recorded with local government, had low levels of education and were not prepared.

Table 4: Mean score on KAP based on the attendance of training courses

\begin{tabular}{llll}
\hline Aspects & Yes $(\mathbf{N}=\mathbf{4 7})$ & No (N=3) & p-value \\
\hline Knowledge & $83.3 \pm 1.46$ & $79.0 \pm 2.51$ & 0.24 \\
Attitude & $87.0 \pm 3.49$ & $88.0 \pm 3.0$ & 0.65 \\
Practice & $91.2 \pm 1.72$ & $83.4 \pm 2.08$ & 0.74 \\
\hline
\end{tabular}

$\mathrm{N}=50$; Values were expressed as mean \pm standard deviation; a significance difference between the means $(\mathrm{p}<0.05)$ by T-test

\section{GMP Knowledge's}

Overall means for the knowledge level was $83.00 \pm 1.51$, in good level. The majority of the respondents (98\%) answered the question related to the definition of GMP correctly. They were likewise aware that applications of proper hygiene can reduce the danger of infection to patients with $98 \%$ agreed. Siow and Norrakiah [4] also stated that more than half of the respondents $(73.9 \%)$ served with the right option which indicates that they realized food prepared without proper handling may contribute to the risk of foodborne illnesses. This indicated they had defended the fact from MOH [2] that one of the identified reasons for foodborne diseases is hygiene status.

The categories of knowledge exhibited consisted of three important elements in manual GMP that should be pursued. It consists of monitoring food temperature, high-risk foods, and personal hygiene. Most of the respondents (98\%) knew that they cannot wear accessories such as watches, earrings, wristbands and others in food processing fields. This result was contrary to observation done by Abdul Mutalib et al. [15], where more than $40 \%$ of their respondent's wear jewelry while working. A study was done by Azanza et al. [22] also shows that only half of the street vendors $(53.7 \%)$ in the Philippines knew that wearing accessories could cause bacterial contamination. Along with this, all should know that having direct food contact with hands of food handlers can increase risks of food contamination.

In this survey, $80 \%$ concurred that they recognized it was not permitted to go into the food processing area where there is an open wound and did not put on gloves. Codex Alimentarius Commission [23] affirmed that sick food handlers who are experienced or suspected of suffering any disease that might be carried by food are not earmarked to exploit or deal with nutrient. Jiang and Doyle [24] in their study mentioned that $94.5 \%$ of their respondents also agreed with this assertion. On the other hand, $94 \%$ of the respondents did know that most important factors to control the development of bacteria in food are time and temperature. Additionally, both of these factors had been evaluated in a study done by Santana et al. [25] at public schools catering in Brazil. After implementation of GMP at school 2 and 10, the temperatures observed in serving step were lower than $65^{\circ} \mathrm{C}$ but the meals were carried for just $30 \mathrm{~min}$ before distribution.

Meanwhile, at school 12, the holding temperature was higher than $65{ }^{\circ} \mathrm{C}$ because the facility received the appropriate equipment to hold hot foods. The result then revealed that bacteria counts were reduced than before GMP being implemented. Fig. 1 shows the knowledge level of respondents about controlling food temperature. The result shows $62 \%$ gave a correct answer regarding food danger 
zone (FDZ) at 5 to $60^{\circ} \mathrm{C}$. Still, $52 \%$ gave the wrong answer regarding range temperature for the chiller that is 1 to $5^{\circ} \mathrm{C}$. Lastly, $82 \%$ of respondents gave the correct answer regarding range temperature for deep-freeze that is $-18{ }^{\circ} \mathrm{C}$ to- $-{ }^{\circ} \mathrm{C}$. The ground of asking respondents about these queries is to assure that awareness of the respondents regarding most important gene in controlling the growth of bacteria is in good level. Nonetheless, this indicated that most of the respondents in this study lacked the knowledge regarding this peculiar issue.

This result was supported by Bas et al. [26], that most respondents lacked knowledge about critical temperatures for ready-to-eat foods, refrigerator ranges, and cross-contamination. Specifically, improper holding temperature and slow cooling of hot foods promote the growth of Bacillus cereus and Clostridium perfringens to diseasecausing levels [27]. In the other study done, Santana et al. [25] had pointed out significant results found for monitoring temperatures during the cooking and serving of the meals before and after implementation of GMP. It was discovered after implementation of GMP; the meals prepared to present low values of aerobic plate count and contaminated by neither staphylococcus coagulasepositives nor thermo tolerant Coliforms. Thus, confirmation of shelf life with a microbial count of foods needs to be tested [28].

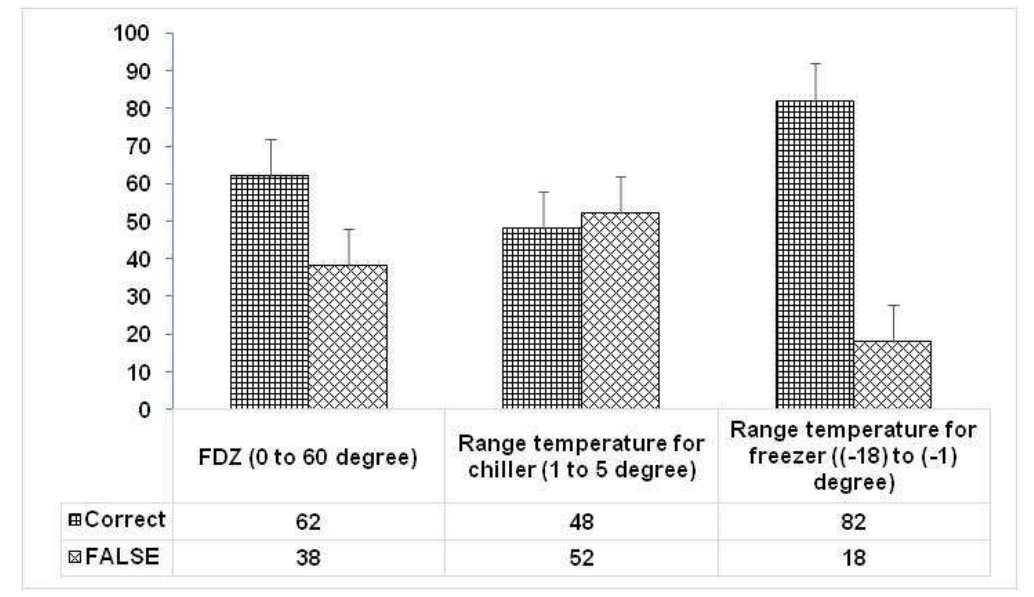

Fig. 1: Knowledge level of respondents about controlled food temperature $(\mathrm{N}=50)$

\section{GMP attitudes}

Overall means for the attitudes was $87.20 \pm 3.42$, in good level. In this study, the majority of the respondents shows good attitude when handling food items. $100 \%$ of the respondents agreed that application of appropriate footwear and waterproof footwear were important to be used in the food production area. As one piece of food handler's responsibilities, to produce safe food is one of the most significant matters. This proved by Siow and Norrakiah [4] in which most of their food handlers $(52.3 \%)$ agreed to take part in whatever training courses (HACCP, GMP, GHP) if giving the chance to them. Attitude is a measure of the degree to which a person has favorable or unfavorable evaluation towards behavior [29]. When the food handlers think that developing and handling food in hygienic condition is important and necessary, they will likely intend to employ in that conduct.

It was brought out in this study when $94 \%$ of the respondents concurred that they must have short fingernails, clean, no 'varnish' or wearing artificial nails. Also in attitudes of hand hygiene, where a majority of them always wash hands before starting work (72\%) and after handling contaminated materials (78\%) has been presented in fig. 2. However, moderately did always wash hands when entering a food handling area (56\%), after the lunch break (56\%) and use a tissue when coughing and sneezing (54\%). In the previous study done by Clayton et al. [30], food handlers might be mindful of the food hygiene attitudes they should have, but $63 \%$ of their respondents admitted that they seldom use such positive attitudes. Therefore, food handlers need to think hygiene attitudes are crucial to be meshed in this arena.

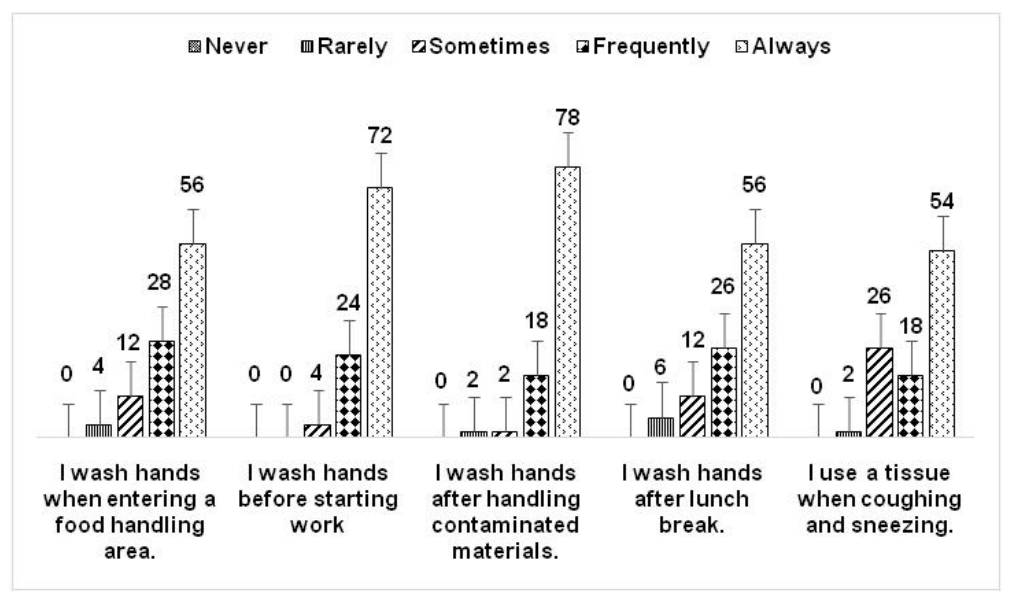

Fig. 2: Percentages of respondent's compliance to an attitude of washing hygiene $(\mathrm{N}=50)$ 
Many of the previous studies also confirmed that it is essential to use self-hygiene, particularly hand hygiene because a hand is a major agent that transmit microorganisms and intestinal parasites to food [31]. $94 \%$ of the respondents did not agree that boxes, containers or boxes that carry dry food items can be set immediately on the base. Likewise, $88 \%$ of the respondents did not check that all boxes or containers that used to store food do not have always been labeled and sealed. This showed that the respondents did read thoroughly questionnaire given. It was found that $38 \%$ of the respondents in this survey agreed that different cloths are used for wiping hands during food formulation, after food production and to clean the floor and aims that are laid right away on the base.

In the survey done by Siow and Norrakiah [4], 56.9\% stated that by not monitoring refrigerator and freezer temperatures might give chances for microorganism growth in the nutrient. This period was also confirmed in this study when $96 \%$ of the respondents concurred that the person in charge should always monitor the refrigerator and freezer temperature so that it is in the appropriate and correct ranges. Saidatul and Hayati [19] had pointed out the result that food handlers at school canteen agreed with the cleanliness monitoring system, that controlled temperature provides a sound feedback for improvement in food hygiene practices and cut food poisoning lawsuits. Positive attitude in handling safe food need to behave by each food handler, but they must agree and believes the importance of safe food handling and barriers to carrying out food safety behavior [32].

\section{GMP practices}

In general, the overall means for the practice level was $90.70 \pm 1.76$, in good level. The respondents practiced good general sanitary when they cleaned immediately liquid once spilled on the floor $(100 \%)$ and washed all equipment employed in the food preparation such as cutting tables, knives, pots and worked surfaces before each time to be employed (100\%). Based on Santana et al. [25], it states the fact that all utensil surfaces exhibited some degree of bacterial contamination illustrates the potential of cross-contamination of surfaces due to the handling of foods and subsequent normal use of the cafeterias. On the other hand, food hygiene practice is extremely critical to ensure safe food production to consumers.

It was found that half of the respondents did maintain safe practices where $76 \%$ concurred that all dry and wet ingredients must be stored followed suitable temperature accordingly. Meanwhile, $6 \%$ prefer a false answer where they agreed dry ingredients does not have to be sorted out from wet ingredients to dilute the danger of cross-contamination. Continuous with this exercise will conduct to the most dominant cause of food intoxication. According to Soriano et al. [33], food poisoning from Staphylococcal mostly occurs resulting from the consumption of food in which enterotoxigenic staphylococci have grown and formed enterotoxin. Another study revealed that $29.3 \%$ of their respondents also did not know that raw and cooked food should be kept separately as keeping them together can cause food poisoning [17].

Nonetheless, food quality and expiration dates must always be held by the person in charge before storage to ensure that fresh ingredients are utilized for food output. This is to secure food production is in full quality without gives harm to human wellness. In this study done, $80 \%$ concurred that the individual in charge must examine the quality of food items and the important dates such as expired date before being utilized for cooking food. Indeed, this statement was also suggested by Campos et al. [34] that food handler must always keep updated about the required procedures for maintaining the quality and safety of food produced in training. The main poor practiced identified in terms of food contact surfaces were less than $50 \%$ of food handlers did state they placed all equipment and food items directly on the base without any pellets or boxes.

Contrarily, the majority of them (98\%) in this study pointed out tools that being frequently used in food production areas and which directly placed on the surface of the floor should be kept clean and free from any contamination. Then, $22 \%$ of the respondents did not cognize that all crates, boxes, food ingredients and food preparation equipment should be located at least 18 " from the rampart. This is one of the most important elements that need to know, operation in flow production, especially in the storage area by implementing GMP. Contrary to that, the majority of the respondents (98\%) did state all food materials should be applied in accordance with the right sequence of First in First Out (FIFO); by conforming to the GMP inspection.

\section{Association between KAP}

A positive correlation was pointed out for three fields each, between cognition and attitudes ( $\mathrm{r}=0.130)$, knowledge and practices $(\mathrm{r}=0$. 238), and between attitudes and practices ( $r=0.420)$. Yet, only level practices and attitudes shows significant correlation with a $\mathrm{p}<0.05$. This indicates that knowledge's level of food handler influence both food handler's attitudes and practices in handling food in the food serving field. Besides, it demonstrates their attitude level influences their practices in minimizing foodborne diseases. An effectiveness of the GMP sessions and its implementation were evaluated by cleaning and sanitation, maintenance of equipment and utensils and operation of current production. Instead of that, educational training is one of the most significant elements in GMP.

Table 5: Correlation (Pearson) among KAP-level of respondents

\begin{tabular}{lll}
\hline Level & $\mathbf{R}$ & p-value \\
\hline Knowledge-attitudes & 0.13 & 0.37 \\
Knowledge-practices & 0.24 & 0.10 \\
Practices-attitudes & 0.42 & $<0.05^{* *}$ \\
\hline
\end{tabular}

$\mathrm{N}=50$; Correlation is significant at the 0.05 level $(2$-tailed $)(\mathrm{P}<0.05)$

However, Pilling et al. [35] had stated that knowledge delivered by training courses cannot just be translated into desired changes in attitudes and practices. There were also studies pointed out that knowledge, education alone was not sufficient to enhance the hygienic practices and attitudes from food handlers [36, 37]. Thus, Philip and Anita [38] suggested that some managers must be proactive and support the food handlers to transfer the acquired knowledge into desired attitudes in order to assure a safe supply of food by providing them with resources and support needed to assist in the transition. Vladimirov [39] had pointed out the correlation of positive conduct, attitudes and continued training of food handlers towards the maintenance of safe food handling practices.

Contradict with Bas et al. [40] in their study that establishes the attitude scores of the food handlers toward foodborne disease prevention was poor as well as hygiene practice scores were even lower. These studies have done so, although training may increase knowledge to carry out good food hygiene but it might not always turn out positive changes in food handler's attitudes. In the other position, motivation from supervisors and management as well as the funding and facilities devoted to food staff are utmost important to the success of food safety education training [4]. If continuous and well-oriented educational training is offered to food handlers, prevention of foodborne diseases and correct sanitation procedures could be easily improved [41].

\section{CONCLUSION}

Overall, this study had achieved the objectives that being listed. The findings indicate that food handlers in four Terengganu hospitals have a good level of knowledge (83.0 \pm 1.51$)$, attitudes $(87.2 \pm 3.42)$ and practices $(90.7 \pm 1.76)$ regarding GMP. However, the majority of the respondents also shows the lack in several questions in KAP session on GMP. The connection between socio-demographic data factors and variables of level KAP on GMP had significant value. The sociodemographic data involves were gender, ages, working experiences and attendance at training classes. This study done showed that the attitude domain had the significant association with the age groups and the working experience with the value of $p<0.05$. This suggested that respondents with increases ages and increases working experiences had shown positive attitude when handling foods.

On the other hand, a positive correlation was pointed out for the three domains each, between knowledge and attitudes $(\mathrm{r}=0.13)$, knowledge 
and practices $(\mathrm{r}=0.24)$, and between attitudes and practices $(\mathrm{r}=0.42)$. Yet, only level practices and attitudes shows significant correlation with $\mathrm{p}<0.05$. This cross-sectional study has various limitations that necessitate being played up. Firstly, it was done in a single position, just 4 different districts of Terengganu hospitals involved and it may not be representative of all hospitals in Terengganu state. This work could have been represented Terengganu hospitals by including food handlers from each hospital in this state and then the consequences can be generalized within this state.

Furthermore, the data from the questionnaires have relied on selfreporting from food handlers that might exhibit bias as no confirmation taken during the culmination of the questionnaires by the respondents, who may have misinterpreted questions and response options. A questionnaire is often capable of studying large samples of people fairly easy and immediate. This instrument is capable of analyzing a large number of variables and can ask respondents to reveal behavior and attitudes which have been seen in actual places. For improvement in future surveys, various suggestions were highlighted in this survey. It is proposed that the questionnaires regarding elements of GMP should be thoroughly included in order to examine food handler's levels of KAP closely.

Such examples are the specific temperature of internal cooked meat, poultry, vegetables, details knowledge of equipment rules in the food operation area, inspection on hand washing behavior of food handlers for several days and others. Aside from that, it would be worthwhile if future studies can start out the cooperation again from government offices such as the $\mathrm{MOH}$, health institutions or other related agencies so that all food handlers from hospitals can be reviewed and therefore increased the strength and awareness of the GMP study. A food handling campaign towards KAP of the GMP study could be an example for more specific step.

\section{ACKNOWLEDGEMENT}

This study was approved by Medical Research and Ethics Committee, Ministry of Health Malaysia with registration number NMRR-14-58521283 and ethics committee from the UniSZA Human Research Ethics Committee with reference number UniSZA. N/1/628-1 (61). A special thankful to Dr. Myat Moe Thwe Aung, Puan Hjh Ramlah Hj. Ali and my research colleagues throughout the survey and statistical input. The cooperation of food handlers in Terengganu hospitals is appreciated. Extra thanks as well to all collaborative researchers who participated in this survey and for steering.

\section{CONFLICTS OF INTERESTS}

\section{Declared none}

\section{REFERENCES}

1. World Health Organization (WHO). Conference on health in times of conflict. Publ-Univ Toronto, Inst Environ Stud; 2014. p. 11-3.

2. Ministry of Health Malaysia (MOH). Annual Report; 2012. p. 385.

3. Kapoor D. Impact of pharmaceutical industries on the environment, health and safety. J Crit Rev 2015;2:25-30.

4. Siow ON, Norrakiah AS. Assessment of knowledge, attitudes, and practices (KAP) among food handlers at residential colleges and canteen regarding food safety. Sains Malays 2011;40:403-10.

5. Kale MA, Bindu SM, Khadkikar P. Role of antioxidants and nutrition in oxidative stress: a review. Int J Appl Pharm 2015;7:1-4.

6. Centers for Disease Control and Prevention. Antibiotic resistance threats in the United State 2013. Threat Report; 2013. p. 1-14.

7. Jevsnik M, Hlebec V, Raspor P. Consumers' awareness of food safety from shopping to eating. J Food Qual Hazards Control 2008;19:737-45.

8. Acikel $\mathrm{CH}$, Ogur R, Yaren $\mathrm{H}$. The hygiene training of food handlers at a teaching hospital. J Food Qual Hazards Control 2008;19:186-90.

9. Norrakiah AS, Siow ON. Knowledge, attitudes and practices of food handlers on food safety in food service operations at the University Kebangsaan Malaysia. J Food Qual Hazards Control 2014;37:210-7.

10. World Health Organization (WHO). Health systems: improving performances. Bull WHO; 2000. p. 1-33.
11. Food Hygiene Regulations. Food Safety and Quality Division. Ministry of Health Malaysia (MOH); 2009.

12. Food and Agriculture Organization/World Health Organization (FAO/WHO). Regional conference on food safety for the Asia and the Pacific, Seremban; practical actions to promote food safety. FAO Corporate Document Repository; 2004. p. 1-21.

13. Bansal G, Parashar B, Dhamija H. The application of HACCP and risk management in the pharmaceutical process. Asian J Pharm Clin Res 2013;6:21-5.

14. Marais M, Conradie N, Labadarios D. Small and micro enterprisesaspects of knowledge, attitudes, and practices of managers Hospital, Western Cape. South Afr J Clin Nutr 2007;20:50.

15. Abdul-Mutalib NA, Abdul-Rashid MF, Mustaf S, Amin-Nordin S, Hamat RA, Osman M. Knowledge, attitude and practices regarding food hygiene and sanitation of food handlers in Kuala Pilah, Malaysia. J Food Qual Hazards Control 2012;27:289-93.

16. Askarian M, Kabir G, Aminbaig M, Memish Z, Jafari P. Knowledge, attitudes, and practices of food service staff regarding food hygiene in Shiraz, Iran. Infection Control Hospital Epidemiol 2004;25:16-20.

17. Gritlioglu I, Batman 0, Tetik N. The knowledge and practice of food safety and hygiene of cookery students in Turkey. J Food Qual Hazards Control 2011;22:838-42.

18. Maizun MM, Nyi NN. Socio-demographic characteristics of food handlers and their knowledge, attitude and practice towards food sanitation: a preliminary report. University Sains Malaysia 2002;33:410-8.

19. Saidatul AAA, Hayati MD. Food handler's attitude towards safe food handling in school canteens. Social Behavioral Studies 2013;105:220-8.

20. Sharif L, Al-Malki T. Knowledge, attitude and practice of Taif university students on food poisoning. Food Control 2010;21:55-60.

21. Rajiah K. A cross-sectional survey on knowledge, attitude and practice of staff members towards daily water intake during working hours in international medical University, Malaysia. Asian J Pharm Clin Res 2012;5:143-5.

22. Azanza MPV, Gatchalian CF, Ortega MP. Food safety knowledge and practices of street food vendors in a Philippines university campus. Int J Food Sci Nutr 2000;51:235-46.

23. Codex Alimentarius Commission. Recommended international code of practice, general principles of food hygiene. CAC/RCP 1e1969; 2003. p. 4.

24. Jiang XP, Doyle MP. Fate of Escherichia coli 0157:H7 and Salmonella enteritidis on currency. J Food Prot 1999;62:805-7.

25. Santana NG, Almeida RCC, Ferreira JS, Almeida PF. Microbiological quality and safety of meals served to children and adoption of good manufacturing practices in public school catering in Brazil. J Food Qual Hazards Control 2009;20:255-61.

26. Bas M, Ersun AS, Kivanc G. The evaluation of food hygiene knowledge, attitudes and practices of food handlers in food businesses in Turkey. J Food Qual Hazards Control 2004;17:317-22.

27. McCabe-Sellers BJ, Beattie SE. Food safety: emerging trends in foodborne illness surveillance and prevention. J Am Diet Assoc 2004;104:1708-17.

28. Nisha P, Sheela S. Nutritive value, acceptability, antioxidant activity and storage stability of Hibiscus Rosa Sinensis incorporated ready to eat powders. Int J Curr Pharm Res 2015;7:89-91.

29. Azjen I, Fishbein M. Understanding attitudes and predicting social behavior. Prentice Hall Inc; 1980.

30. Clayton DA, Griffith CJ, Price P, Peters AC. Food handler's beliefs and self-reported practices. Int J Environ Health Res 2002;12:25-9.

31. Aarnisalo K, Tallavaara K, Wirtanen G, Maijala R, Raaska L. The hygienic working practices of maintenance personnel and equipment hygiene in the finnish food industry. J Food Qual Hazards Control 2006;17:1001-11.

32. Mitchell RE, Fraser AM, Bearon LB. Preventing food-borne illness in foodservice establishments: Broadening the framework for intervention and research on safe food handling behaviors. Int J Environ Health Res 2007;7:9-24.

33. Soriano JM, Font G, Molto JC, Manes J. Enterotoxigenic staphylococci and their toxins in restaurant foods. Trends Food Sci Technol 2002;13:60-7. 
34. Campos AKC, Cardonha AMS, Pinheiro LBG, Ferreira NR, Medeiros de Azevedo PR, Stamford TLM. Assessment of personal hygiene and practices of food handlers in municipal public schools of Natal, Brazil. J Food Qual Hazards Control 2009;20:807-10.

35. Pilling VK, Brannon LA, Shanklin CW, Howells AD, Roberts KR. Identifying specific beliefs to target to improve restaurant employees' intentions for performing three important food safety behaviors. J Am Diet Assoc 2008;108:991-7.

36. Chang HJ, Lee JS, Kwak TK. The effectiveness of HACCPbased training on the food safety knowledge and behavior of hospital food service employees. J Nutr Sci 2003;6:11826.

37. Walker E, Pritchard C, Forsythe S. Food handler's hygiene knowledge in small food businesses. J Food Qual Hazards Control 2003;14:339-43.
38. Phillip S, Anita E. The efficacy of the theory of planned behavior model in predicting safe food handling practices. J Food Qual Hazards Control 2010;21:983-7.

39. Vladimirov Z. Implementation of food safety management system in Bulgaria. Br Food J 2011;113:50-65.

40. Bas M, Ersun AS, Kivanc G. Implementation of HACCP and prerequisite programs in food businesses in Turkey. J Food Qual Hazards Control 2006;17:118-26.

41. Park SH, Kwak TK, Chang HJ. Evaluation of the food safety training for food handlers in restaurant operations. Nutr Res Practice J 2010;4:58-68.

\section{How to cite this article}

- Norhaslinda R, Norhayati AH, Mohd Adzim Khalili R Knowledge, attitudes and practices (KAP) on good manufacturing practices (GMP) among food handlers in terengganu hospitals. Int J Pharm Pharm Sci 2016;8(11):53-59. 